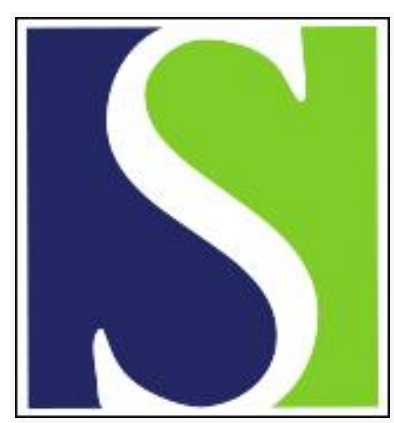

Scand J Work Environ Health 1986;12(4):423-427

https://doi.org/10.5271/sjweh.2119

Issue date: Aug 1986

Measures of vibrotactile sensitivity in persons exposed to hand-arm vibration.

by Hayward RA, Griffin MJ

This article in PubMed: www.ncbi.nlm.nih.gov/pubmed/3775333

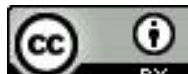




\title{
Measures of vibrotactile sensitivity in persons exposed to hand-arm vibration
}

\author{
by Robert A Hayward, BSc, Michael J Griffin, PhD'
}

\begin{abstract}
HAYWARD RA, GRIFFIN MJ. Measures of vibrotactile sensitivity in persons exposed to hand-arm vibration. Scand J Work Environ Health 12 (1986) 423-427. A group of 57 persons occupationally exposed to hand-arm vibration was studied in an investigation of factors affecting their vibrotactile thresholds. The group contained 42 persons with symptoms of vibration-induced white finger (VWF). Measures of finger thresholds and temperatures were obtained from both hands. It was found that vibrotactile thresholds were higher in subjects reporting VWF. A laboratory investigation indicated that finger temperature had a great effect on the thresholds but that this effect only occurred outside the range of temperatures found in the study of occupationally exposed persons. Laboratory research showed that vibrotactile thresholds should be expected to depend upon vibration exposure immediately prior to the test. The vibration frequency and general configuration of the vibrotactile apparatus also influenced threshold. An awareness of these factors allows guidelines for their control to be suggested.
\end{abstract}

Key terms: diagnosis, finger temperature, thresholds, vibration-induced white finger.

Measures of vibrotactile thresholds in vibration-exposed workers have been advocated as a diagnostic aid for vibration-induced white finger (VWF). However, there are other factors than VWF which may influence vibrotactile thresholds. These factors may relate to the method used to determine the thresholds (eg, vibration frequency, contactor geometry, site of the test, practice effects) or to intrasubject variables (eg, recent vibration exposure, finger temperature) or to intersubject variables (eg, lifetime vibration exposure, alcohol consumption, smoking, age) or to the presence of various medical conditions (eg, primary Raynaud's phenomenon, other secondary Raynaud's phenomenon, cardiovascular disease, nervous system disease, medication).

This paper examines some of these factors in relation to the results of laboratory studies, as well as those of a small-scale study with vibration-exposed workers.

\section{Vibrotactile test procedure}

The apparatus and procedure used in the study were developed with reference to laboratory studies and to the experimental literature. It is thought that vibrotactile perception is mediated by two types of receptors in glabrous skin, Meissner's corpuscles, sensitive to low-frequency vibration $(<10$ to $>70 \mathrm{~Hz}$ ), and pacinian corpuscles, sensitive to high-frequency vibra-

\footnotetext{
Human Factors Research Unit, Institute of Sound and Vibration Research, The University, Southampton SO9 5NH, England.
}

Reprint requests to: Mr RA Hayward, Human Factors Research Unit, Institute of Sound and Vibration Research, The University, Southampton SO9 5NH, England. tion $(<50$ to $>500 \mathrm{~Hz})$. There is considerable overlap of the two regions.

It is desirable to test vibrotactile thresholds at two frequencies, the perception of which is mediated by different receptor types. The vibrotactile apparatus consisted of a counterbalanced vibrator carrying a 6-mm diameter perspex-tipped circular contactor, extending up through a 10-mm diameter solid perspex surround. This contactor touched the finger with a force of $1 \mathrm{~N}$. An up-down method of limits was employed, the subject depressing a hand-held response button when he could feel the vibration. The rates of stimulus change were $0.15 \mathrm{~ms}^{-2} / \mathrm{s}$ and $0.10 \mathrm{~ms}^{-2} / \mathrm{s}$ for stimuli of 63 and $125 \mathrm{~Hz}$, respectively. The subjects were required to produce six consistent reversals for each threshold determination. The work of Verrillo (6) would suggest that, with the contactor geometry used in this study, the frequencies of 125 and $63 \mathrm{~Hz}$ would be differentially mediated. A fixed surround aids repeatability and also restricts the area of the stimulus.

\section{Study with vibration-exposed subjects}

\section{Subjects and methods}

The subjects were 57 male metal workers employed on hand-held and pedestal grinders in the forging industry. Their ages ranged from 21 to 61 years with a median of 54 years. Their period of vibration exposure ranged from 1 to 44 years with a median of 23 years. Two subjects with blanching not related to vibration exposure were excluded. 


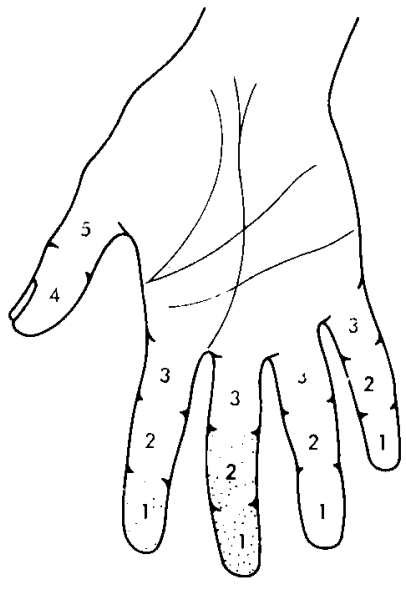

Right Hand

\begin{tabular}{|c|c|c|c|c|c|}
\hline Digit & Th. & 1 & 2 & 3 & 4 \\
\hline $\begin{array}{c}\text { Possible } \\
\text { Score }\end{array}$ & $4+5$ & $1+2+3$ & $1+2+3$ & $1+2+3$ & $1+2+3$ \\
\hline $\begin{array}{c}\text { *Actual } \\
\text { Score }\end{array}$ & 0 & 1 & 3 & 0 & 0 \\
\hline $\begin{array}{c}\text { Total } \\
\text { Score }\end{array}$ & $4 / 33$ \\
\hline
\end{tabular}

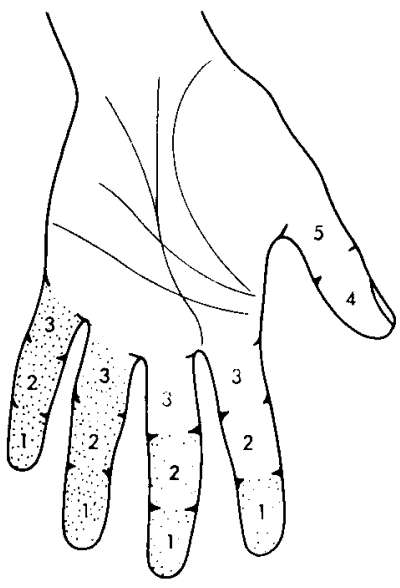

Left Hond

\begin{tabular}{|c|c|c|c|c|c|}
\hline Digit & Th. & 1 & 2 & 3 & 4 \\
\hline $\begin{array}{c}\text { Possible } \\
\text { Score }\end{array}$ & $4+5$ & $1+2+3$ & $1+2+3$ & $1+2+3$ & $1+2+3$ \\
\hline $\begin{array}{c}\text { *Actual } \\
\text { Score }\end{array}$ & 0 & 1 & 3 & 6 & 6 \\
\hline $\begin{array}{c}\text { Total } \\
\text { Score }\end{array}$ & \multicolumn{5}{|c|}{$16 / 33$} \\
\hline
\end{tabular}

Figure 1. Method of scoring reports of blanching.
Each subject came straight from his workplace to pass through the following three stages of study:

1. Medical questionnaire: A questionnaire, administered by a nursing officer, gathered information on the subjects' history of relevant medical disorders, social factors (smoking and drinking behavior) and reported symptoms (blanching, tingling, and numbness). The extent of blanching was assessed by a numerical scoring system in which a total score out of 66 for all 10 digits was obtained (3). This method is illustrated in figure 1.

2. Medical examination: An examination by a doctor included some functional tests on the hands of the subject and a more general medical examination. The doctor provided a diagnosis as to whether white finger was present and, if so, whether it was VWF or due to some other cause. He also made a diagnosis of any other relevant medical factors (eg, carpal tunnel syndrome).

3. Exposure questionnaire and objective tests: A short questionnaire was employed to arrive at a history of the subjects' vibration exposure, determining the type of tool used, the pattern of usage, and the years of use.

Skin temperatures were then measured on the distal pads of all 10 digits with an array of thermocouples mounted in a perspex block with shaped indentations for each digit to insure good contact between the thermocouple and the skin. Room temperature was determined at the same time.

The thresholds were determined at 63 and $125 \mathrm{~Hz}$ on the distal pads of each digit and on the base of both thumbs. A practice session consisted of one threshold determination at each frequency with the index finger of the subjects' dominant hand. The 12 sites were then tested in a quasi-random order.

\section{Results}

Forty-two subjects were diagnosed as having VWF. Two subjects with blanching not related to vibration were excluded from the analyses. For subjects with VWF, $50 \%$ had blanching scores greater than 12/33 on the worst affected hand.

The relation of VWF to vibrotactile thresholds in this population can be seen in figure 2 for thresholds at each test frequency. The thresholds were not significantly different from one digit to another for the unaffected subjects. For all digits there was a significant difference between the thresholds of those with and those without blanching.

Figure 3 shows the median thresholds on a single digit (right-hand index) for each blanching score on the digit. The only significant differences were between the scores of zero and all the other scores.

Smoking has been frequently cited as a factor in VWF. In the studied population (table 1) smoking had no effects on either the prevalence of blanching or the vibrotactile thresholds. 


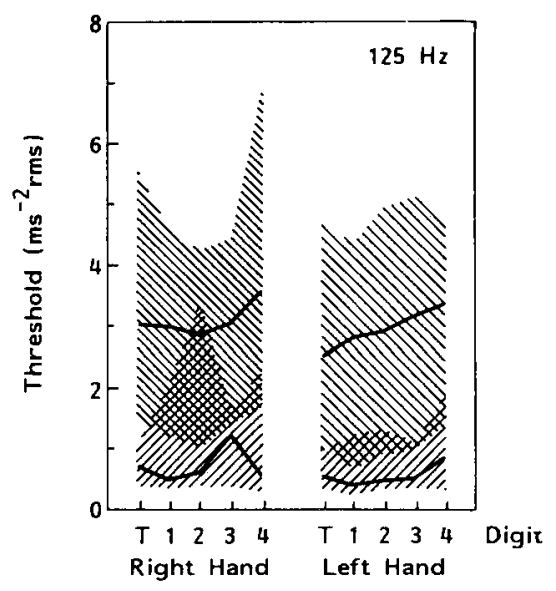

QIII) With VWF

EZT7 Without VWF

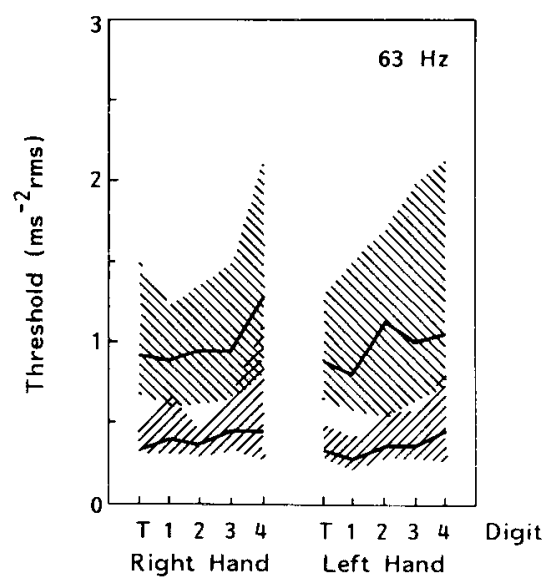

Figure 2. Median vibrotactile thresholds measured on each digit of the vibration-exposed workers with $(N=40)$ and without $(N=15)$ vibration-induced white finger (VWF) (median and interquartile range). (rms $=$ root mean square)

Table 1. Influence of smoking behavior. (VWF = vibrationinduced white finger, rms $=$ root mean square)

\begin{tabular}{lccc}
\hline Group & $\begin{array}{c}\text { Percentage } \\
\text { with VWF }\end{array}$ & $\begin{array}{c}\text { Mean 125-Hz } \\
\text { threshold } \\
\left(\mathrm{ms}^{-2} \mathrm{rms}\right)\end{array}$ & $\begin{array}{c}\text { Mean 63-Hz } \\
\text { threshold } \\
\left(\mathrm{ms}^{-2} \mathrm{rms}\right)\end{array}$ \\
\hline Smokers & 73 & 2.66 & 0.85 \\
Nonsmokers & 72 & 2.77 & 0.99 \\
\hline
\end{tabular}

Other authors $(7,5)$ have earlier suggested that age may have an effect on vibrotactile thresholds of the general population. Figure 4 shows the relationship obtained in this study. There was a tendency for the thresholds to rise with increased age.

Figure 4 also shows the relation of the blanching score to age. The findings suggest that the effect of age on vibrotactile threshold may be partly due to in-

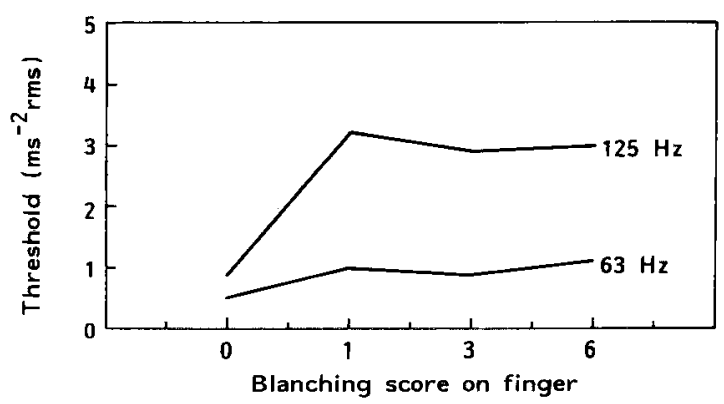

Figure 3. Median vibrotactile thresholds of the right-hand index finger of the vibration-exposed workers. (rms = root mean square)
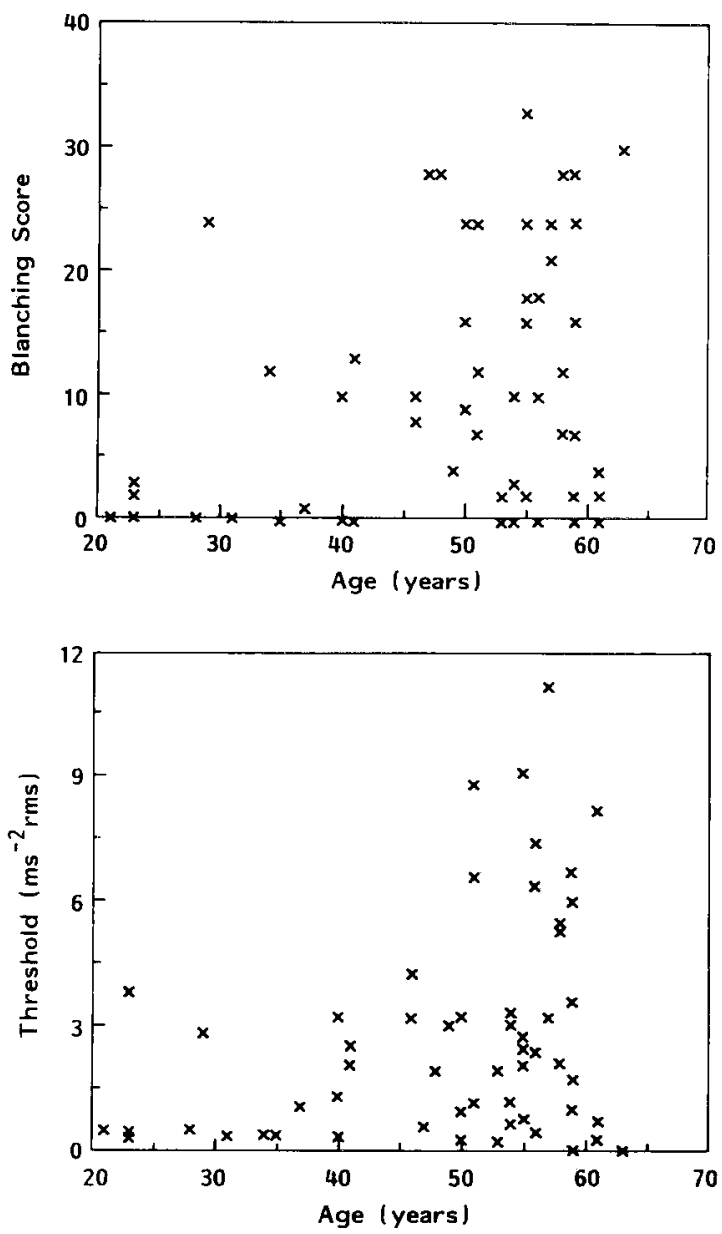

Figure 4. Relationship of the blanching score of the right hand $(0-33)$ and the $125-\mathrm{Hz}$ threshold of the right-hand index finger to the age vibration-exposed persons. $(\mathrm{rms}=$ root mean square)

creased blanching among older subjects. In addition the degree of exposure, rising with age, may influence the threshold. The small number of subjects and the skewed age distribution make it difficult to determine 
Table 2. Influence of previous vibration exposure. $(\mathrm{rms}=$ root mean square)

\begin{tabular}{lcc}
\hline Group & $\begin{array}{c}\text { Mean 125-Hz } \\
\text { threshold } \\
\left(\mathrm{ms}^{-2} \mathrm{rms}\right)\end{array}$ & $\begin{array}{c}\text { Mean } 63-\mathrm{Hz} \\
\text { threshold } \\
\left(\mathrm{ms}^{-2} \mathrm{rms}\right)\end{array}$ \\
\hline $\begin{array}{l}\text { No exposure } \\
\text { on day of test }\end{array}$ & 4.96 & 0.98 \\
$\begin{array}{l}\text { Exposure on } \\
\text { day of test }\end{array}$ & 4.89 & 1.20 \\
\hline
\end{tabular}

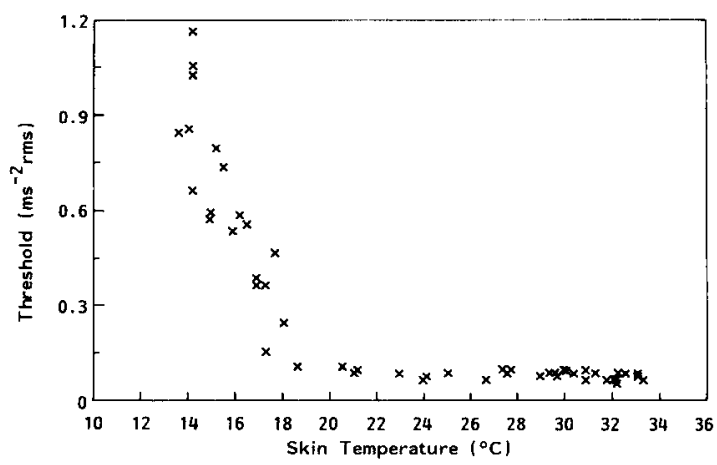

Figure 5. Effect of skin temperature on the $125-\mathrm{Hz}$ threshold of a laboratory subject. ( $\mathrm{rms}=$ root mean square)

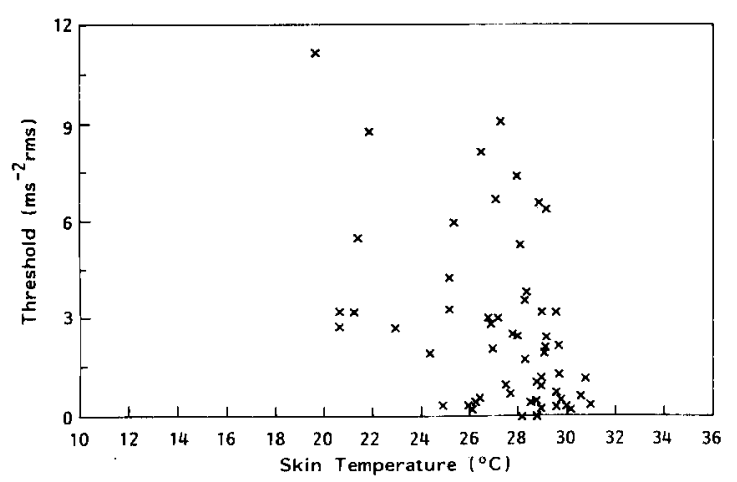

Figure 6. Effect of skin temperature on the $125-\mathrm{Hz}$ threshold of vibration-exposed persons. ( $\mathrm{rms}=$ root mean square)

statistically the effects of these three factors on the present results.

\section{Possible artifactual influence}

Vibration exposure immediately preceding the measurement of vibrotactile threshold produces a temporary threshold shift $(1,4)$. It is desirable to test subjects free from the effects of threshold shifts induced by their work. Laboratory studies suggest that the time course of recovery is rapid in unexposed subjects even when the exposure is severe. A single normal subject was exposed to $2 \mathrm{~h}$ of $80-\mathrm{ms}^{-2}$ root-mean-square (rms) sinusoidal vibration at $125 \mathrm{~Hz}$, delivered through a rigid handle firmly gripped. The $125-\mathrm{Hz}$ threshold immediately after the exposure was $1.75 \mathrm{~ms}^{-2} \mathrm{rms}$ in comparison to the base line of $0.18 \mathrm{~ms}^{-2} \mathrm{rms}$. The recovery was virtually complete after $30 \mathrm{~min}$. That the time course was of comparable length in a work environment can be seen by from a comparison of thresholds of subjects starting a workshift (ie, with no vibration exposure in the preceding $12 \mathrm{~h}$ ) with those of subjects using vibrating tools in the period immediately preceding the test (table 2 ). There were no significant differences, and therefore it is suggested that the 30- to 45-min period during which the medical questionnaire and examination were administered was sufficient to eliminate any effect of temporary threshold shifts.

Skin temperature is known to affect vibrotactile thresholds $(2,8)$. A laboratory study on a single unexposed subject, measuring thresholds and finger temperature while the room temperature was varied between 8 and $32^{\circ} \mathrm{C}$, showed that thresholds on the right-hand index finger only started to rise at finger temperatures below $20^{\circ} \mathrm{C}$ (figure 5). This value is outside the range of finger temperatures measured in the field study (figure 6).

\section{Discussion}

To assess the relation of vibrotactile thresholds to blanching, it is first necessary to control other factors that may influence thresholds. (See the Introduction.) From the results obtained in the measurement of thresholds in a small sample of exposed subjects, some initial guidelines may be suggested to control for these factors.

1. Subjects with medical conditions that may influence results can be identified by a medical questionnaire and examination. Their results can be looked at with consideration for the possible confounding effects of the medical conditions.

2. Some intersubject variables may have little effect (eg, smoking). However, it is necessary to collect data on these factors to insure that confounding effects do not occur.

3. Some variables (eg, age) may have a significant influence. The size of this effect can be assessed in an unexposed population, and, if necessary, the test results collected in an exposed population may be corrected.

4. The effects of some variables can be controlled by specifying procedural constraints, for example, inclusion of measurements of finger temperature to insure it is greater than $20^{\circ} \mathrm{C}$. 
5. The test procedure should take account of timedependent variables and therefore insure that the subject is in a controlled environment for a length of time sufficient to eliminate the effects of, for example, temporary threshold shifts.

6. The test apparatus and method should be selected to maximize repeatability and to eliminate artifacts.

\section{Acknowledgments}

This research was conducted with the assistance of the Health and Safety Executive and GKN (Forgings) Ltd.

\section{References}

1. Bjerker N, Kylin B, Lidstrom I-M. Changes in the vibratory sensation threshold after exposure to powerful vibration. Ergonomics 15 (1972) 399-406.

2. Green BG. The effect of skin temperature on vibrotactile sensitivity. Percept Psychophys 21 (1977) 243-248.

3. Griffin MJ. The effects of vibration on health. University of Southampton, Southampton (England) 1982. (ISVR memorandum 632).

4. Lidstrom I-M, Hagelthorn G, Bjerker N. Vibration perception in persons not previously exposed to local vibration and in vibration-exposed workers. In: Brammer AJ, Taylor W, ed. Vibration effects on the hand and arm in industry. John Wiley \& Sons, New York, NY 1982, pp 59-65.

5. Steinberg FU, Gruber AL. The effect of age and peripheral circulation on the perception of vibration. Arch Phys Med Rehabil 44 (1963) 645-650.

6. Verrillo RT. A duplex mechanism of mechanoreception. In: Kenshalo DR, ed. The skin senses. Charles C Thomas, Springfield, IL 1966, pp 139-159.

7. Verrillo RT. Changes in vibrotactile thresholds as a function of age. Sens Process 3 (1979) 49-59.

8. Weitz J. Vibratory sensitivity as a function of skin temperature. J Exp Psychol 28 (1941) 21-36. 